\title{
AVERTISSEMENT
}

La Bibliothèque Publique de Toronto a entrepris, avec la collaboration de la Maison des Sciences de l'Homme (Paris), du Conseil Canadien de Recherches sur les Humanités et du Conseil Canadien de Recherches en Sciences sociales, un programme de réimpressions comportant quelque deux cents texts sur l'histoire du Canada et des Etats-Unis. Ces ouvrages, choisis par un Comité des Conseils et la Bibliothèque Publique de Toronto, ont tous été publiés en édition originale avant 1867: environ le tiers d'entre eux sont en langue française.

Les livres sont réimprimés au format de l'édition originale et, sauf en ce qui concerne la reliure, en fac-similé de celle-ci. La reliure et le papier sont conformes aux normes recommandées par le Council on Library Resources quant à leur solidité et leur durabilité. Chaque volume comporte en supplément une note bibliographique, reproduite d'apres la Bibliographie des Canadiana publiée par la Bibliothèque Publique de Toronto.

La collection "Canadiana avant 1867" répresente une source de documentation unique en son genre pour tous ceux qui s'intéressent à l'histoire de l'exploration et de la colonisation de l'Amérique du Nord. 



\section{SIX LECTURES}

SUR

L'A N N EXION DU

Canada aux Etats - Unis. 



\title{
SIX LECTURES
}

SUR

\section{L’A N NEXION}

\section{CANADA AUX ETATS - UNIS,}

\author{
PAR L. A. DESSAULLES.
}

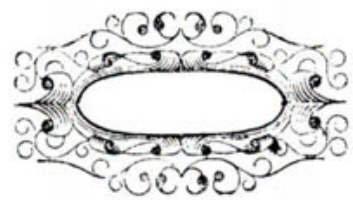

MONTREAL:

IMPRIMÉ E'T PUBLIE PAR P. GENDRON; TYP. 29, RUE ST. GABRIEL. 1851. 
